\title{
THE MICROBIAL AND FUNCTIONAL DIVERSITY OF THE MICROFLORA PRESENT ON THE SCALPS OF INDIAN SUBJECTS WITH AND WITHOUT DANDRUFF
}

Rituja SAXENA ${ }^{1}$, Parul MITTAL ${ }^{1}$, Darshan B DHAKAN', Prashant HEGDE², Mahesh M VEERANAGAIAH ${ }^{2}$, Subarna SAHA', Nita ROY ${ }^{2}$, Lionel BRETON, Namita MISRA ${ }^{2,3}$, Cecile CLAVAUD', Audrey GUENICHE', Vineet K SHARMA'
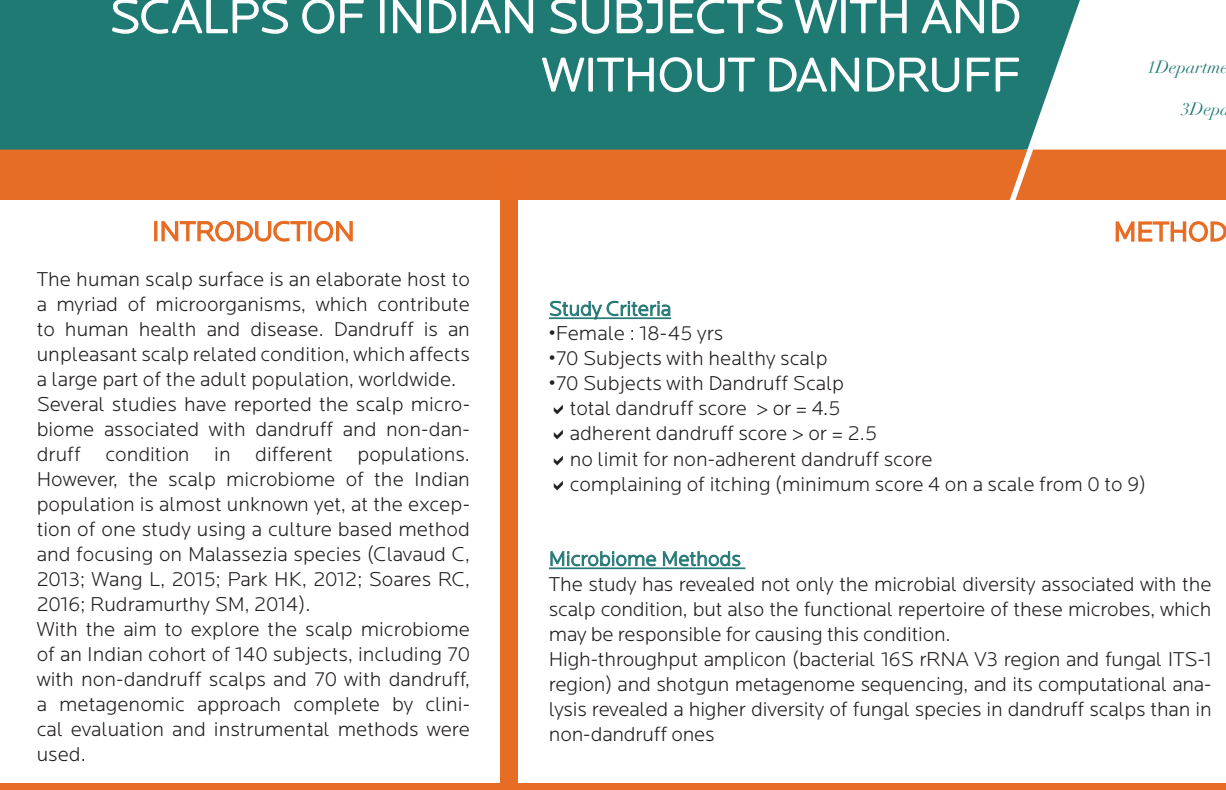

1Department of Biological Sciences, Indian Institute of Science Education And Research, Bhopal, India
2Department of Advanced Research, Loreal India Pot. Ltd, Bengalore, India 3Department of Advanced Research, Loreal Research de Innovation, Aulnay sous bois, France

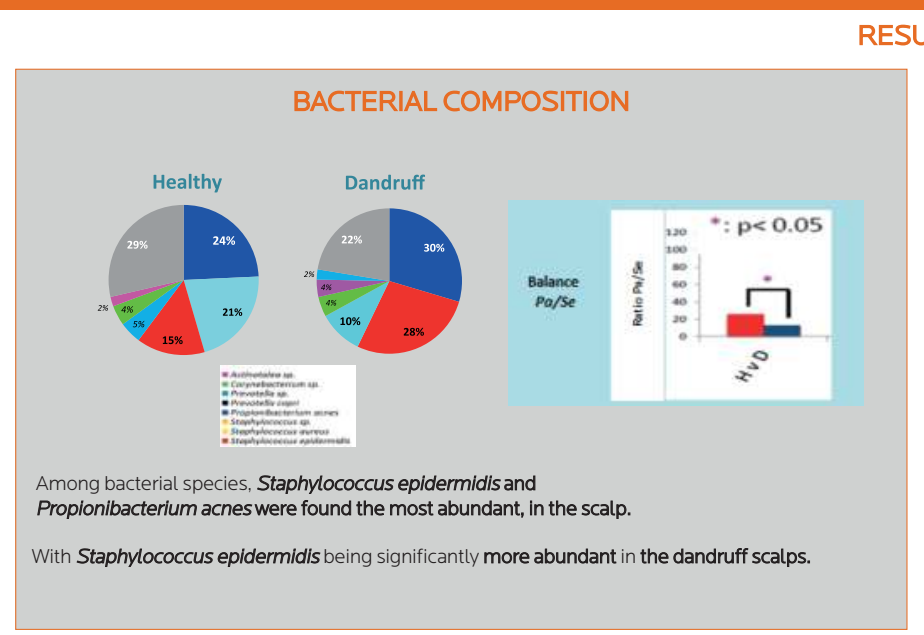

RESULTS

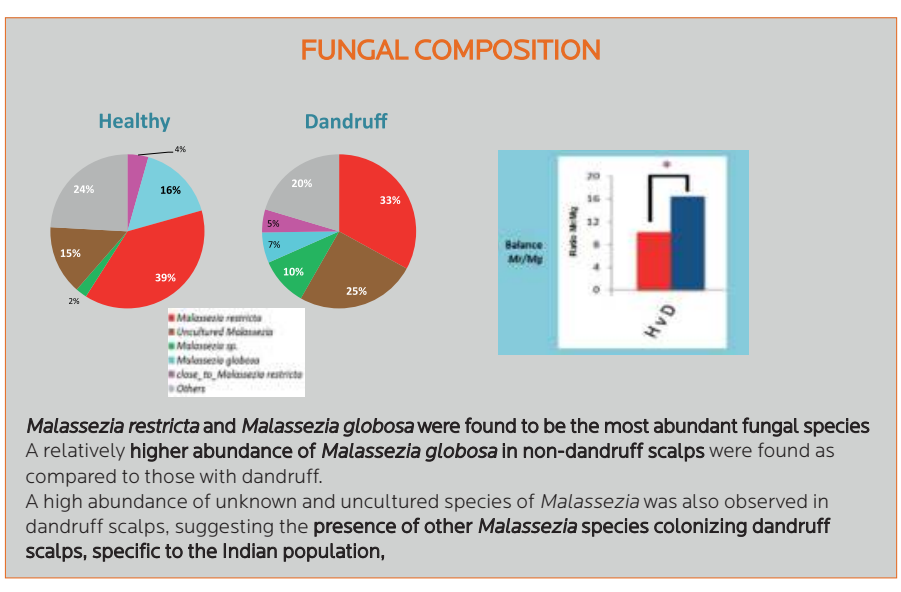

The microbial community also showed significant correlations with clinical parameters associated with the host tissue

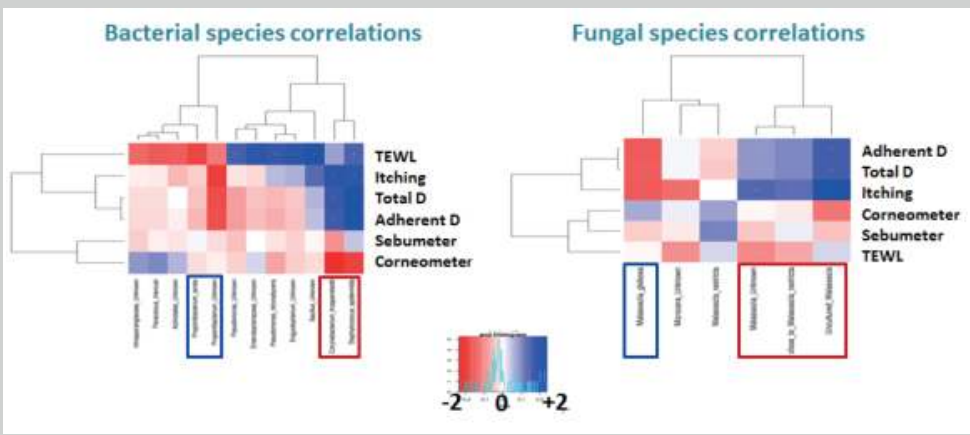

- Dandruff scalp is characterized by high dandruff scores, itching and TEWL - Sebumeter is difficult to measure in dandruff (absorbe by squamous) nevertheless sebumeter is correlate in this study positively with $\mathrm{S}$. epidermidis, $M$. restricta

- Corneometer correlates negatively mainly with S. epidermidis and C.

kroppenstedti but also with Malassezia uncultured

-TEWL correlate with Corynebacterium, Propionibacterium, some Malassezia sp

\section{CONCLUSION}

SImllary to litterature data S. epidermidis and P. acnes are anticorrelated In the context of dandruff vs healthy also In Indlan populatlon. Dandruff In Indlan population Is also assoclated with Uncuttured-Malassezia.

The Indlan specificity Is the correlation of healthy scalp parameters with :

- M. globosa

- potentlal new subspecles of $M$. restricta.

-And particular sp. of Propionibacterium 